\title{
The Token Female: Women's Experiences as Division I Collegiate Head Coaches of Men's Teams
}

\author{
Cindra S. Kamphoff, Suzannah M. Armentrout, Andrew Driska \\ Minnesota State University
}

\begin{abstract}
Fifteen women who coach NCAA Division I men's teams were interviewed about their experiences coaching men. Six themes emerged after a comprehensive analysis of the interview transcripts: 1) Gender barriers experienced by women coaching men, 2) Obtainment of their position coaching men in unique ways, 3) Women coach only men's minor sports, 4) Characteristics contributing to their success coaching men, 5) Reasons for a lack of women coaching men, and 6) Strategies for change. Findings confirm previous research on women coaching men (i.e., Kane \& Stangl, 1991) and point to the tokenism and marginalization that women coaching men experience. Unique findings of this study included that women have to be decorated athletes or coaches to coach men, many of the women in this study were unaware of the opportunity to coach men, and athletic director support is key in the success of women who coach men.
\end{abstract}

As numerous scholars contend, sport continues to be one of the most obvious social institutions in which socially constructed beliefs about gender benefit men (Hall, 1996; Theberge, 1993; Thorngren, 1990). Sport is a uniquely powerful tool in society because it provides a location for men to reaffirm their masculinity and to display power, leadership, and authority (Theberge, 1993). For example, the dominant forms of sport in the U.S. demand strength, aggression, and courage-all of which are congruent with the notion of masculinity, not femininity.

This connection of masculinity to sport impacts the experiences of both male and female coaches at all levels of sport. Staurowsky (1990) argued that this underlying assumption perpetuates the notion that coaching male athletes is an exclusive responsibility of male coaches. Hence, women who work in the system of sport experience an automatic devaluation of their achievement and experiences because sport is so closely tied to masculinity. In fact, Kamphoff (2010) contends that U.S. collegiate coaching has been exclusively defined as "men's work" where a "good coach" is seen as a "male coach." All of the former female collegiate coaches who she interviewed discussed the privileging of males and male teams within U.S. collegiate athletics and described how female coaches are compared against the standard of male coaches.

The authors are with the Department of Human Performance, Minnesota State University, Mankato, MN. 
Acosta and Carpenter's (2010) most recent longitudinal report investigating the employment opportunities for coaches and administrators at the U.S. collegiate level clearly points to the gendered nature of coaching and administration and supports the claim that sport is directly tied to masculinity. They report the decline of women coaches within collegiate athletics stating that women comprised over $90 \%$ of collegiate coaches of women's teams and administrators before the passage of Title IX in 1972, but only $42.6 \%$ of coaches and $19.1 \%$ of administrators in 2010. When looking closer at the head coaches of male teams, between $1.5 \%$ and $3 \%$ of men's teams are coached by a female. This small percentage has remained consistent since the passage of Title IX in 1972. It is, however, likely that the actual number of women coaching men has increased since Title IX due to the increase of men's teams (Brand, 2003). Yet, the actual number of women coaching men is very small; in fact, Acosta and Carpenter (2010) report between 175 and 225 women coach a collegiate men's team. Similarly, Yiamouyiannis' (2007) recent research confirmed the small number and percentage of women coaching men. She reported that roughly only $2 \%$ (or 195) of all men's collegiate teams at the NCAA Division I, II and III levels had a female head coach during 2005. These data, taken together, points to the gendered nature of U.S. collegiate coaching and documents the lack of female coaches and the absence of females coaching men's teams.

Much of the existing literature concerning females in the coaching profession, however, has focused exclusively on women coaching female athletes and sport teams (Kamphoff, 2010; Inglis, Danylchuk, \& Pastore, 2000; Theberge, 1993; Thorngren, 1990). Rarely, however, has research focused on women's experiences coaching males and to date only a few studies exist (Kane \& Stangl, 1991; Staurowsky, 1990; Yiamouyiannis, 2007). In one of those studies, Kane and Stangl (1991) investigated the employment patterns of women as coaches of men's high school sport teams in Ohio. Using Kanter's (1977) theoretical framework, Kane and Stangl found that females represented "token" members because they represented less than $15 \%$ of the coaching profession. Their data also suggested that the female coaches who coached males experienced marginalization specifically because they were significantly more likely to coach less prestigious sports for men, which have lower status and power within collegiate athletics (i.e., individual sports compared with team sports).

Another researcher (Staurowsky, 1990) examined women coaching boys at the high school level and interviewed female coaches of traditional all-male sports teams (i.e., basketball, baseball, football, soccer, and lacrosse). Staurowsky reported that all female coaches she interviewed met resistance, experienced discrimination, and had to work harder to appear as or more competent than their male colleagues. The women described how they received sexist wisecracks specifically from male coaches, had difficulty establishing authority with male athletes and male coaches, and experienced glances and gestures from other male teams they competed against. For instance, many times the women described that they were mistaken for athletic trainers, relatives, reporters, statisticians, managers or even potential dating companions instead of head coaches.

More recently, Yiamouyiannis (2007), who conducted one of the only studies focusing on women coaches of men's teams at the collegiate level, surveyed women head coaches of NCAA Division I, II, and III men's teams. The majority 
$(95 \%)$ of the women she surveyed served as head coaches of combined men's and women's teams with the majority of women coaching men's cross country, track and field, swimming, tennis or golf. Women in her sample faced unique gender barriers including job access, workplace discrimination, expectations that they should possess feminine qualities, and agency barriers. Yiamouyiannis concluded that women aren't applying for collegiate coaching positions specifically because they do not see jobs coaching men as open to them, they lack societal support, they receive lower salaries than their male counterparts, and athletic directors are not hiring women to coach men.

Given the general lack of the research focused on women coaching men and the fact that the majority of this research was conducted roughly 20 years ago (i.e., Kane \& Stangl, 1991; Staurowsky, 1990), more research is needed to better understand the experiences of women coaching men to potentially increase the number of women coaching men and improve their experiences. Gaining an understanding of women's experiences coaching men is particularly important because of the lack of women coaching men (Acosta \& Carpenter, 2010), and research that points to the marginalization, discrimination, and resistance they experience when they do coach men (Kane \& Stangl, 1991; Staurowsky, 1990; Yiamouyiannis, 2007). Therefore, the central aim of this study was to better understand the experiences of current NCAA Division I female coaches of men's teams. Women NCAA Division I head coaches of men's teams were chosen for this study because generally there is more prestige in coaching NCAA Division I and the athletic talent is higher compared with NCAA Division II or III (Coakley, 2004). Hence, this study was designed to gain a better understanding of how these women obtained their positions coaching men within NCAA Division I, and specific barriers that exist for women coaching men at this level.

\section{Method}

\section{Participants}

Fifteen women who coached an NCAA Division I men's sport team were interviewed. The mean age of the women coaches was 41.6 years old $(S D=6.76$; ranging from 26 to 54). The sports the women coached included: track and field and cross country, track and field only, cross country only, tennis, golf, squash, swimming and diving, and rowing. The women had been coaching at the collegiate level at the time of the interviews for an average of 13.1 years $(S D=5.62$; ranging from 7 months to 19 years), and had been coaching men at the collegiate level on average for 7.6 years $(S D=5.04$; ranging from 7 months to 17 years). The majority of the women indicated their race as Caucasian/European American $(n=12)$, with 2 African Americans and 1 Native American in the interview sample. All but two of the women $(n=13)$ indicated their marital status as married, whereas one women stated she was divorced and another was single. Nine of the 15 women indicated they had children which ranged in age from $51 / 2$ months to 21 years old at the time of the interviews. The average coaching salary for the women interviewed was $\$ 56,300$ ( $S D=26,226$; ranging from $\$ 24,500$ to $\$ 120,000)$. 


\section{Procedures}

After Institutional Review Board approval, selection of a purposeful sampling of women NCAA Division I head coaches of male teams began. Specifically, we searched all NCAA Division I athletic department websites for women head coaches of male teams. Cohead coaches $(n=2)$ were eliminated from the sample to ensure that the women interviewed were the main or primary coach of the men's team. This search resulted in 41 women who were head coaches of men's teams. This number is similar to Yiamouyiannis' (2007) search in 2005 that resulted in 50 NCAA Division I women head coaches of men's teams.

Within this population of 41 women, only 2 women coached a men's only team, whereas 37 of the 39 coached both men and women. All but one of the women in the population coached an individual sport $(97.6 \%, n=40$ of 41$)$, and the majority $(70.7 \% ; n=29$ of 41$)$ coached men's cross country and/or track and field. The sports the women coached included: both cross country and track and field, cross country only, track and field only, tennis, golf, rowing, swimming and diving, squash, and equestrian.

Interview participants were then selected from this list of 41 women by looking closely at the biographies listed on their university's websites to select the most successful women coaches of men's teams. Success was determined by the conference that the men's team competed within, the team's national finish within the last several years and/or recent awards the coach had received. The women who were selected were then sent an e-mail invitation to participate in the study. All women agreed to participate in the study and each was individually interviewed over the phone using a semi-structured interview guide. Phone interviews were used to reach women throughout the country. The interview guide was developed based on previous research (c.f., Kane \& Stangl, 1991; Staurowsky, 1990; Yiamouyiannis, 2007). Sample questions on the interview guide included: "How did the opportunity to coach men come about for you?" and "Given your experiences, what advice would you give a female friend who is considering coaching men at the collegiate level?" The interviews ranged in time from $45 \mathrm{~min}$ to $1 \mathrm{hr}$ and $10 \mathrm{~min}$. The interviews were tape-recorded and transcribed verbatim. A saturation point where no new data emerged (Creswell, 1998) was reached after 15 interviews; therefore, no other interviews were conducted.

\section{Analytic Strategy}

A descriptive analytic strategy described by Creswell (1998) was used when analyzing and interpreting the interview data. Specifically, the content from each interview was divided into individual statements. This process first began as the first and second authors read the transcripts thoroughly, highlighted key phrases on the transcripts, and wrote overlying conceptual labels in the margins of the transcripts. These conceptual labels were constantly compared with each other to reduce the number of labels, differentiate labels, and to show a relationship among them. Then, passages from the transcripts were placed into categories and labeled with the overlying theme of the passage. All passages with similar statements were labeled with the corresponding theme. To explain the essence of the women's experiences, a textual description of each theme was written and statements from the women are provided. Through this process, the themes were developed based upon the frequency of comments and significance of comments that occurred during the interview process. 


\section{Establishing Trustworthiness}

Scholars of qualitative research methods are in agreement that trustworthiness is essential to establish to determine the accuracy of the findings (see Creswell, 1998 for a discussion). More specifically, establishing trustworthiness provides credibility to the qualitative research and decreases researcher bias. Creswell described eight procedures that researchers can engage in to establish trustworthiness in qualitative research and he suggested at least two of the procedures be used. These eight procedures include: prolonged engagement, triangulation, external audits, clarifying researcher bias, rich and thick description, peer review or debriefing, negative case analysis, and member checks. As such, the following four procedures to establish trustworthiness were used in this study: prolonged engagement, triangulation, external audits, and rich and thick description.

First, to become as familiar as possible with each participant's experience, the first and second author engaged in prolonged engagement with the interview data. Each transcript was read multiple times by authors. Second, through a process called triangulation, the three authors met regularly to develop and identify the themes to reduce research bias. More specifically, after reading the transcripts thoroughly, the first and second author developed the themes independently and presented them at the research meeting. The themes were then compared and finalized over the course of multiple research meetings. Third, three other external auditors who were involved in various aspects of the research study read between two and five of the transcripts and verified the final themes. Fourth, while presenting the results, an attempt was made to include rich and thick descriptions. For instance, direct quotes were used whenever possible to provide support for the themes and to describe the women's experiences.

\section{Results}

After a comprehensive and extensive analysis of the interview transcripts, six general themes emerged: 1) gender barriers experienced by women coaching men, 2) obtainment of their position coaching men in unique ways, 3) women coach only men's minor sports, 4) characteristics contributing to their success coaching men, 5) reasons for a lack of women coaching men, and 6) strategies for change.

\section{Theme 1: Gender Barriers Experienced by Women Coaching Men}

All of the women interviewed discussed barriers they experienced because they were a woman coaching a men's collegiate team. Although the women discussed many gender barriers, the most frequently discussed included: 1) credibility and respect issues with athletes, parents, officials and/or community members $(n=14)$, 2) difficulties recruiting male athletes $(n=11), 3)$ experiencing a "token" status in which they were the only female coaching men $(n=10)$, and 4) difficulties establishing professional relationships with male coaches $(n=9)$.

Difficulty Establishing Credibility and Respect. Difficulty establishing credibility and respect with athletes, parents, officials, and/or community members was mentioned by almost all of the women interviewed $(n=14)$. When describing 
the difficulty women who coach a men's team experience when trying to establish credibility, a golf coach said that people believe, "She's a woman...she doesn't belong here... what is she doing coaching men?"

About half of the women discussed that the first several years they coached the men's team was particularly difficult because they did not recruit the current men on their team and some parents had difficulty with their son being coached by a woman. A tennis coach described that during her first year coaching the men's team a father raised a concern about her ability to coach to the athletic director stating, "What is she going to teach my son? How is she going to make him a better tennis player?" The tennis coach felt that this type of questioning reflected "the belief that a woman can't teach a man to play tennis." Furthermore, the women coaches described that at times community members couldn't believe that they were a coach of a men's team and many times approached their male assistant coaches or even their male athletes instead of talking with them. One coach, for example, described a time that she was checking in her men's team to a hotel and the clerk approached the male athlete standing next to her. She said,

One time I was going to check into a hotel. I'm 38. You can tell I'm the oldest one in the crowd. I definitely look older than 18-22. I'm the one that has the jacket on that says "Coach." I've got the clipboard in my hand. I look like I'm the one in charge. And the guy behind the counter looked at me, looked at the 22 year old athlete standing next to me, and then looking him in the eye said, "Can I help you?"

Difficulties Recruiting Male Athletes. Eleven of the fifteen women discussed difficulties they experienced recruiting male athletes. Many women said that they believed there are male athletes who would not play for a female coach. For example, a track and field coach said, "There are certain athletes that aren't going to come to school here because I'm a female" whereas another track and field coach explained the difficulties she experienced while recruiting male athletes stating, "I can't get them in to visit. I can't even get them on our campus." Several of the women discussed that the reason recruiting is a difficult process is because the male athletes have never had a female coach. A track and field and cross country coach said, "If the male athlete has only been coached by males, then there's going to have to be a barrier that has to come down before you move forward [in the recruiting process]."

Experiencing a "Token" Status. Ten of the women described a "token" status (Kanter, 1977) in which they were the only female coaching men at various locations including their university, conference, within their sport, and at coaches meetings. For example, one coach said that women coaching men have "been in the minority for years" whereas another woman stated that females coaching men is "very, very rare." Similarly, one woman described her experiences reflecting on when she realized that she was "the only one." She said,

I remember at one point looking around and I didn't see hardly any women coaching men at the Division I level. There were very few... probably two others that I knew of, and I don't even know if they were actually head coaches or not. 
Having a "token" status presented difficulties in numerous ways and in some cases being the only woman coaching men made the women feel ostracized and alone. For example, a golf coach described a situation at a coaching convention where she was getting an award. She said,

One time, I was down at the coaches' convention... I was getting my ten-year award. I'm the only woman in the room. Three hundred people and I'm the only one. We're getting our awards and they're calling everybody's name and telling what school they are from. [A colleague] names a couple guys and I'm waiting for him to get to my name. And the guy stood up there at the podium in front of our whole congregation and said, "Somebody from [her university]." Swear to God. . probably the only woman to get a 10 year award in the association. And he said "Somebody from [her university]." I looked around, I didn't know what to do I was so embarrassed. And I stood up and said my name out loud and I just walked up and got my award. But I thought, "That son of a bitch, he did that on purpose."

Difficulties Establishing Professional Relationships with Male Coaches. Nine of the women also discussed difficulties they experienced establishing professional relationships with other male coaches. In fact, a few described that they had more difficulty with other male coaches than their male athletes. Some of the women discussed the predominance of the "good ol' boys club" or "goodfellas club." One golf coach stated that she believed that her team was not invited to certain tournaments because her team was coached by a female and other coaches didn't want to lose to a female coach. She said, "You know, they don't want to get beat by a woman who is a coach." Furthermore, a few of the women discussed the difficulties that they have had with their male assistant coaches. A track and field and cross country coach described her perception stating,

I've talked to female coaches across the country. Often they get faced with having to let a male coach go just because that male coach cannot be comfortable with their role under a female coach.

\section{Theme 2: Obtainment of Their Position Coaching Men in Unique Ways}

All of the fifteen women interviewed discussed how they obtained their position coaching men and included: eight were initially coaching the women's team and the men's and women's programs were combined, four were approached to apply for the position by administrators or the former coach, and only three of the women actually set out to apply for a position coaching men. In fact, the majority of the women had no intentions of coaching men, but thought they were just in the "right place at the right time." For example, a golf coach stated, "It's funny, cause I did not go out seeking to try to coach men...I'll be honest, I never really thought about coaching men too much before [obtaining this coaching position]." Similarly, another coach stated, "It wasn't that I went, 'Ah man I'd love to really go coach guys.' It was just, hey there's a coaching opportunity there." Additionally, a cross country and track coach said that she "Didn't set out to coach men to make 
any point, of anything like that, it was just the situation that I was in." The specific ways the women obtained their position are outlined below.

Initially Coaching the Women's Team. Over half of the women interviewed ( $n$ $=8$ ) were initially coaching the women's team at their university, and eventually coached the men's team. At the time of the interview, all eight women were coaching both the men's and women's teams. Half $(n=4)$ of these eight women discussed that the decision to combine the men's and women's programs was financially driven. For instance, a track and field coach said:

It was the athletic director's decision to streamline our positions, because we don't have a lot of resources to throw five coaches in the mix. So we had four coaches total...Probably in their mind, it did save some money...It came across more as, staff-wise, this made more sense to have one program.

Approached to Apply. Four of the fifteen women interviewed were approached to apply for their coaching position by the athletic director, another administrator in the athletic department (in one case the senior women's administrator), or the former coach. In fact, the two women interviewed who coached only the men's team were both approached to apply for the position coaching men. A tennis coach described this process:

When [the former coach] resigned, [a member of the administration] approached me about combining the programs and doing both. I had done a very good job of elevating that women's program in a lot of ways: resources, funding, and scheduling. They just felt that I could bring that same sort of scheduling and resources into the men's program.

Directly Applied For the Position. The other three women interviewed directly applied for the position coaching the combined men and women's programs after becoming aware of the open coaching position. A track and field coach described when she applied:

The administration had made the decision from a practical standpoint in terms of hiring coaches and from a financial standpoint to combine their men's and women's programs. So the position was advertised as a dual gender coaching role and I applied.

\section{Theme 3: Women Coach Only Men's Minor Sports}

Without a prompt during the interview, all of the fifteen women discussed the trend that women coach only men's minor sports. Most of the women use the term "minor sports" whereas a few used the terms "men's Olympic sports" and "men's individual sports." The women discussed sports such as cross country, golf, swimming and diving, track and field, and tennis as more likely for women to coach. Several of the women were quick to point out that women rarely coach men's baseball, basketball and football and if they did coach these sports, "it would make the news." For example, a track and field coach said, "You've never seen a woman coaching men's basketball at any division." The women provided a few reasons for this trend including: 1) men's minor sports receive less emphasis and support 
within the collegiate athletic department $(n=9), 2)$ men's minor sports are more likely to have a combined team of both men and women $(n=8), 3)$ men in minor sports are more likely to have had a female coach previously $(n=5)$, and 4$)$ the technique is similar in men's minor sports when coaching men and women $(n=4)$.

Men's Minor Sports Receive Less Emphasis and Support. The most frequent reason the women provided ( $n=9$ ) was that men's minor sports receive less emphasis within the collegiate athletic department. This was talked about in relation to a "tier system" where resources and funding are lower for men's minor sports. For example, a few of the women mentioned that men's minor sports do not produce revenue for the athletic department and, therefore, are usually lower on the tier system. A tennis coach described the tier system in collegiate athletics specifically within her university,

Tennis is a tier 4 sport at our university and that's kind of the recognition that we get and sometimes I feel we are less fortunate. We don't get what football gets, and we don't get what other tier 1, 2, or 3 sports get either....that is a definite barrier for us.

Men's Minor Sports Are More Likely To Have a Combined Team with Women. Eight of the women also said that a reason women tend to coach men's minor sports compared with other sports is that the culture within men's minor sports is more "tolerant of" women in authority positions because the sports are typically combined (i.e., a men's and women's team). For example, a track and field coach stated that because the sport is typically combined in terms of coaching, having a woman coach is more likely. She said,

The nature of our sport being both genders allows this to happen. I don't think you're ever going to see a female coaching men's baseball or basketball or something that is just separately male.

Men Who Compete in Minor Sports Are More Likely To Have Had a Female Coach. Similarly, five women said that women are more likely to coach men's minor sports because the men who compete in minor sports are more likely to have had a female coach at the youth, high school or club levels. Several $(n=$ 4) women indicated that men are more likely to have a female coach in men's minor sports because the technique in minor sport is similar when coaching men or women. A tennis coach described how female coaches are more likely to coach men in minor sports. She said,

I think it has to do with the sport itself. I think tennis, golf, and swimming, and maybe track, men and women are already combined growing up in that sport. They might already look at women as role models in those sports.

\section{Theme 4: Characteristics Contributing to Their Success Coaching Men}

During the interviews, all of the women discussed the reasons they are successful coaching a men's team and the reasons included: 1) their extensive coaching experience and/or they were very decorated athletes $(n=15), 2)$ support from their athletic director $(n=13), 3)$ a strong coaching philosophy $(n=8), 4)$ support 
from their spouse or partner $(n=6)$, and 5), previous experience coaching a men or boy's team $(n=5)$.

Extensive Coaching or Very Decorated Athletic Experience. The most frequently discussed characteristic that contributed to their success was that all of the fifteen women had extensive coaching experience and/or were very decorated athletes. For example, many of the women coaches were Olympians or All-Americans at the collegiate level. Furthermore, the majority of the women had extensive experience in coaching either at the collegiate, high school, or club levels before being hired in their current position. This experience provided the female coach with credibility, allowed others to accept them as a coach of a men's team, and ultimately allowed them to be hired to coach men. For example, a track and field coach said,

Because I had made Olympic teams and gone beyond just the collegiate level [the administration thought I would be a good coach]. So that I had, in their minds, the ability to take kids further. I could surely accomplish coaching at the collegiate level, having been an All-American in college six times. I think it was more my accolades than anything else.

Support From Their Athletic Director. Nearly all of the women $(n=13)$ discussed that the support from their athletic director contributed to their success coaching men. The ways in which the women described their athletic director included: "he treats everyone fairly and equally" and "very supportive and compassionate." A few of the women stated that their athletic director was particularly supportive of coaches that had families and this contributed to their success.

A Strong Coaching Philosophy. Eight of the women described that a strong coaching philosophy with high expectations was one of the reasons they were successful coaching a men's team at the collegiate level. A swimming and diving coach, for example, said, "I think my high expectations allow me to be successful. I definitely, as a coach, do not accept less than what they are capable of." The women also discussed the importance to having a well-developed coaching philosophy before they began their coaching position and the importance of making decisions based upon that philosophy while coaching.

Support from Their Spouse or Partner. Six of the fifteen women also discussed that the support from their spouse or partner contributed to their success coaching men. These women discussed that without their spouse or partner's support, coaching would not be feasible and this was particularly true for the women who had children. In general, the women described that it was important for their spouses to have flexible schedules to support their time-consuming job as a collegiate coach. A crew coach described how her spouse was supportive and his job allowed this flexibility. She explained,

But I'm very lucky in that my husband has a job that's very flexible. He works for himself. And without that, if I had husband that worked an 8 to 5 regular job, I don't know how we'd do it.

Previous Experience Coaching a Men's or Boy's Team. One-third of the women $(n=5)$ also described their previous experience coaching a men or boy's team as a reason for her success coaching men. This experience ranged from coaching a 
boy's team at the club or high school level to an assistant coaching role for a collegiate team. In addition, one-third of the women $(n=5)$ also discussed that their experience with males as sons, brothers or fellow athletes competing with men contributed to their success coaching men.

\section{Theme 5: Reasons for a Lack of Women Coaching Men}

During the interviews, all of the fifteen women provided their perception of why there is a lack of women coaching men. The most frequent reason the women identified was that coaching men is only socially acceptable for women to coach "certain" men's sports $(n=10)$. These sports included men's minor sports that are typically individual in nature (See Theme 3 for a more complete description). Other reasons which will be discussed below included: 1) women coaches of men's teams face discrimination and difficulty gaining respect $(n=8), 2)$ women coaches of men's teams have difficulty balancing coaching and family responsibilities $(n=7)$, 3 ) women are unaware of the option to coach men $(n=6)$, and 4) women coaches in general receive low salaries and especially coaching men's teams $(n=6)$.

Women Coaching Men Face Discrimination and Difficulty Gaining Respect. Eight of the fifteen women discussed that another reason for a lack of women coaching men is because women coaches of men's teams face discrimination and difficulty gaining the respect of athletic administrators, athletes, other coaches, and parents (see Theme 1). A track and field coach was insistent that men in power positions such as the athletic director are more likely to hire male coaches. She described:

Males hire males... You can call it stereotypes, gender barriers, perception, [a lack of] confidence in women as not being able to do as good of a job as men, or whatever. But you look at history, and this is what happened. All of the power positions were [held by the] men and they were doing the hiring. And all of a sudden the women stopped being hired as much as the men. I hate to say it but that's kind of reality.

Women Coaching Men Experience Difficulty Balancing Work and Family. Almost half of the fifteen $(n=7)$ women discussed the difficulty for women coaches to balance coaching and family responsibilities. The women described balancing work and family as "very, very difficult" and impossible without an extremely supportive partner or spouse. One track and field coach specifically discussed that she and her husband decided not to have children because of how difficult she perceived it to be to balance her coaching career with having children. One coach discussed the trend of women leaving coaching in general because of the difficulty of balancing coaching with family. She stated that unless you have a partner who has flexibility in their life, "it's very, very hard to do what we do." Furthermore, a track and field coach also discussed how she perceived it to be more common for the women in a traditional partnership to be willing to make "sacrifices" for their husbands to further their careers then it is for husbands to do the same. She stated:

When people go into partnerships, either a marriage or a relationship, it's a lot more common and easier for the female to be very supportive of the male in a coaching position. And really pick up all the slack for that guy who's climbing 
the ladder and committing 24-7 to his job, than it is for a female to have a partner who is willing to do that.

Women Are Unaware of the Option To Coach Men. Because it is uncommon for women to coach men, six of the women discussed that they were unaware of the option to coach men. One woman commented, "I think there's that fear of the unknown, women coaching men is not very common and so you just don't assume that you can do it." One track and field coach specifically stated that female athletes lack the mentorship to consider college coaching as a career. She stated,

I think women just aren't tracked into the mindset of being a college coach. I think guys have a little bit more mentoring from the young age up to be like you could be a coach, you could be a coach.

Women Coaches of Men's Teams Receive Low Salaries. Six of the fifteen women also discussed the low salary for women coaches in general, and specifically for women who coach men's teams as a reason for the lack of women coaching men's teams. Women coaches of men's team described the low salary as "really far behind" and "horrible." A tennis coach explained, "Either you're supplementing your income doing something else, or you have a partner that has another income. It would be very, very hard to support yourself."

\section{Theme 6: Strategies for Change}

All of the women also described strategies for change to increase the number of women coaching a men's team at the collegiate level and improve their experiences coaching a men's team. The five most frequently discussed strategies are presented and include: 1) change athletic director's perceptions of women coaching men $(n=$ $7), 2$ ) more accommodations for women coaches with families $(n=7), 3)$ daycares on campus or within athletic departments $(n=5), 4)$ more mentoring for women coaches $(n=5)$, and 5) increase the salary of women coaching men's teams $(n=3)$.

Change Athletic Director's Perceptions of Women Coaching Men. Nearly half $(n=7)$ of the women specifically described that changes in athletic directors' perceptions of women coaching men was needed to increase the number of women in coaching and improve their experiences. A track and field coach had a suggestion that athletic directors should view women assistant coaches as potential head coaches. She said that,

It's going to take a change in the athletic director's viewpoints. Instead of seeing those assistant coaches as just assistants... [the athletic director should] actually meet with them and spend some time developing them as well and giving them opportunities.

She also argued that athletic directors should promote female coaches to cohead coaches to increase their opportunities at their university as well as others.

More Accommodations for Women Coaches with Families. Nearly half of the women $(n=7)$ stated that there needs to be more accommodations for women coaches with families to keep them in coaching and increase the number of women coaching men. A cross country and track and field coach indicated that more 
children are traveling with women coaches and this should be viewed as more acceptable if they bring a "nanny, sister, husband, or somebody to help with the kids." She continued,

Women that are having children are bringing them to the meets in the last several years. They're not leaving their job. They made the decision to bring their kids with them...Because you can't have a child and leave from Thursday until Sunday, you can because a lot of my colleagues will leave them with their spouse but if you're a female you can't. You can't leave a 6 month-old for 4 or 5 days every week, you can't do it.

Daycares on Campus or within Athletic Departments. Four of these 7 women also discussed the need for a daycare on campus or within the athletic department. For instance, a swimming and diving coach said that "if there were daycares on all college campuses, it would make it 100 times easier because your child is right down the street or right downstairs."

More Mentoring for Women Coaches. Four of the women also discussed the need for more mentoring of women coaches and the importance of establishing a network for women coaches. For example, a cross country and track and field coach specifically pointed to older women coaches to provide this mentorship,

I think that women need stronger and more role models... I think that older women coaches have to take that responsibility on to really mentor people and embrace them. I think whether young coaches admit it or not they need mentors.

Increase the Salary of Women Coaches of Men's Teams. Three of the women also indicated that increasing the salary of women coaches who coach men is essential and would increase the number of women coaching men. The women indicated that "more money" is important, as well as a higher salary would allow women with children to hire a nanny to travel with them. Furthermore, two women suggested that an earlier exposure of women coaching men at the youth, high school or club levels would increase the number of women coaching men and then women coaching men "wouldn't be anything unusual." A tennis coach, for instance, said,

To be honest with you I think it has to start earlier then the college level. It has to start with boys being around women coaches and having the respect and knowing that those women have something to offer. That they have an experience and knowledge to help them grow in their sport. So whether it's in youth soccer or youth basketball, this is important.

\section{Discussion}

The purpose of this study was to better understand the experiences of current NCAA Division I female coaches of men's teams. Understanding women's experiences coaching men is particularly important because of the lack of women coaching men (Acosta \& Carpenter, 2010), and research that points to the marginalization, discrimination, and resistance they experience when they do coach 
men (Kane \& Stangl, 1991; Staurowsky, 1990; Yiamouyiannis, 2007). Consistent with previous research, women experienced barriers when coaching men due to their gender including difficulties establishing credibility, recruiting male athletes, and establishing professional relationships with male coaches (Staurowsky, 1990). In addition, similar to Kane and Stangl (1991), women experience both tokenism and marginalization while coaching men. A discussion on how this study relates to this previous research will follow along with a focus on how these findings are unique. Thus, this section will be subdivided into five areas: 1) the token woman coaching men, 2) the marginalization of women who coach men, 3 ) women need to be extremely decorated athletes and/or coaches to coach men, 4) women are not aware of the opportunity to coach men, and 5) administrative support is key. A section outlining future research and limitations will also be discussed.

\section{The Token Woman Coaching Men}

Two-thirds of the women in this study described a token status in which they were only female coaching men at various locations including their university, conference, within their sport, and at coaches meetings. Kanter (1977) first described tokenism in the corporate setting and explained that it occurs when an underrepresented subgroup in an occupation is comprised of less than $15 \%$ of the overall workforce. Women coaching men are clearly token members of the coaching profession because they represent between $1.5 \%$ and $3 \%$ of all collegiate coaches (Acosta \& Carpenter, 2010), which is much less than the $15 \%$ that Kanter established.

The women in this study were keenly aware of the consequences of their token status while coaching men. They described isolation, difficulties breaking into the network of male coaches and the belief among people they interacted with that women can't and/or shouldn't coach men. Furthermore, the women described difficulties recruiting male athletes and the perception that there are certain male athletes who wouldn't play for a female coach. These findings are similar to those found in previous research. For instance, when observing women managers as a token group, Kanter noted several consequences of underrepresentation that are similar to the experiences of these women. For example, she described that tokens visibly stand out against the dominant group, and they experience isolation from formal and informal communication networks.

Furthermore, Theberge (1993) applied Kanter's (1977) research when interviewing women coaches who had or were coaching women. The women coaches Theberge interviewed were also aware of their token status and provided examples of their isolation. Theberge argued that at the heart of women's token status is the ideology of masculine superiority; specifically, the ideology that males are naturally superior athletes and therefore make the best coaches. The perception that males make the best coaches is confirmed in this study given that the women coaching men experienced resistance from male athletes and fathers, for example, some of whom directly questioned their ability to coach men. Furthermore, the majority of the women had no intentions of coaching men and didn't necessarily see the option of coaching men open to them. In other words, they also perceived that the best coaches of men are male coaches (see the section below entitled, "Women are Not Aware of the Option to Coach Men"). 


\section{Marginalization of Women Who Coach Men}

All of the women in this study coached a men's "minor sport," and all but one of those sports were individual sports compared with team sports. All women interviewed were quick to point out that women only coach sports that are considered "minor," or have less emphasis within the collegiate athletic department. The minor sports these women mentioned included cross country, golf, swimming and diving, tennis, and track and field. This finding is consistent with previous research related to women coaching men (Kane \& Stangl, 1991, Staurowsky, 1990; Yiamouyiannis, 2007).

More specifically, Kanter (1977) described that a second way beyond tokenism that segregation takes place in occupations is through the process of marginalization in which women are in less desirable occupational positions than men. Kane and Stangl (1991) applied Kanter's theory to coaching and argued that women are marginalized into sports with less power, influence and status than male coaches. Kane and Stangl found that women high school coaches in Ohio were marginalized because they were more likely to coach sports that are considered less prestigious; for example, track and field compared with basketball or football. In fact, they concluded that women have been "systematically marginalized into 'lesser' sports, and thus have little, if any, power" (p. 36). This marginalization impacts women from moving into leadership roles within in men's athletics because it "contains" women in less powerful or prestigious sports. Furthermore, the findings from this study reveal a similar trend to those of Kane and Stangl's research which is over 20 years old. Hence, the marginalization of women coaching men is still present and hasn't changed.

Unique to this study was gaining the women coaches' perception of why women only coach men's minor sports. The women perceived that men's minor sports receive less emphasis within the collegiate athletic department; therefore, it is more acceptable for women to coach these sports because resources and funding are less, which further perpetuates the marginalization of women. Furthermore, the women also suggested that women only coach men's minor sports because these sports are typically combined (i.e., a men's and women's team). In fact, of all of the 41 women coaching men at the NCAA Division I level all but one of them coached an individual sport (97.6\%), and the majority (70.7\%) coached men's cross country and/or track and field. These findings suggest that it is more acceptable for women to coach a combined men's and women's team compared with a men's only team which makes it even more difficult for women to break into the coaching ranks.

In addition, the results of this study suggest that when women are hired to coach a men's sport, they rarely only coach men. Of the 41 women coaching men at the NCAA Division I level, only 2 women coached a men's only team, whereas 37 of the 39 coached both men and women. Similarly, Yiamouyiannis (2007) found that 95\% of the NCAA Division I, II, and II women coaching men that responded to her study served as head coach for both a men's sport team and a women's sport team. She found that only 5\% (or 4 out of all of the 79 NCAA Division I, II, and III coaches that responded to her study) were head coach for only a men's team. She concluded that the percentage of all sports teams within NCAA Division I, II, and II who have a head female coach of a men's only team is "extremely low" and "most likely to be lower than one-fifth of 1\%" (p. 114). 


\section{Women Need to be Extremely Decorated Athletes and/or Coaches to Coach Men}

Another unique finding of the current study relates to the background of the women coaches and how the women obtained their coaching position of a men's team. Many of the women were extremely decorated athletes who had competed at the Olympic and/or professional levels. If they weren't extremely decorated athletes, they had extensive coaching experience. It seems, therefore, that to coach men and establish credibility and respect as well as be successful coaching men, women must have a decorated background. This trend is not the case for male coaches. Meaning, men don't need to be extremely decorated athletes or coaches to coach women or men. In fact, many men who coach a collegiate women's or men's team have never played the sport in which they coach.

Although Yiamouyiannis (2007) mentioned that several of the women coaching men in her study indicated they competed at the international or professional level, this finding wasn't as prevalent in her study. She did find, however, that all but one $(98.7 \%)$ of the women in her study was a former athlete and $86 \%$ had experience as an athlete at the collegiate level. Furthermore, over $75 \%$ of the women coaching men in her study had over 6 years of previous coaching experience. One possible explanation for why the findings of the current study suggest a stronger importance of women who coach men having a decorated athletic or coaching background is that the women in this study were all successful NCAA Division I coaches of men's teams (see Method section for participant selection information). Whereas, the women that completed Yiamouyiannis' survey included women who coached men at the NCAA Division I, II, or II levels regardless of their success coaching men. Therefore, having a decorated athletic or coaching background may be particularly important for women to have success coaching men at the NCAA Division I level, the highest level of competition within U.S. collegiate athletics.

\section{Women Are Not Aware of the Option To Coach Men}

Even though many of these women had a decorated background as an athlete or coach, they had not considered coaching a men's team. In fact, half of the women were coaching a women's team at their university when the men's and women's programs were combined. More shocking is that many of the women specifically stated that they had never even considered the possibility of coaching a men's team and never intended to apply for a position coaching a men's team. We conclude that societal perceptions of who can coach men are so prevalent that women are limited in who they perceive they can coach. Certainly, no law exists indicating women can't coach men, but a societal perception is clearly evident.

More specifically, scholars have established that coaching has been defined as a men's profession, where a good coach is considered to be a male coach (Kamphoff, 2010, Staurowsky, 1990, Theberge, 1993). Similarly, Yiamouyiannis (2007) stated that "men are assumed to be competent coaches," whereas women of men's teams must "prove themselves to be competent" (p. 133). These perceptions of who can coach have limited women's opportunities so much that women are not even aware of the option to coach men. In fact, women do not even know they can apply for these positions coaching men. This finding points to the importance of educating 
women that the coaching profession is open to them, and that coaching men is a possibility. Certainly, there are women who are qualified to coach men, but it is important to demonstrate to women that this opportunity is open to them. Perhaps numerous efforts could take place at the organizational level by the National Collegiate Athletic Association, the National High School Association, state high school associations, and/or coaches associations to educate women that this opportunity is available. In addition, popular press articles that showcase women coaching men (c.f., Associated Press, 2010; Gunderson, 2009; Halley, 2010) could provide a mechanism for women to see coaching men and boys as a possibility and address the perception many men and women hold that only males are good coaches. Furthermore, as the women interviewed suggested, educating athletic directors about the opportunities of women coaching men is needed to increase the number of women coaching men and improving their experiences.

\section{Support from Administration Is Key}

Nearly all of the women $(n=13)$ discussed that the support from their athletic director was key to their success coaching men. The women described that a supportive and compassionate athletic director who treats everyone fairly is key to being successful coaching men. Few research studies have investigated the importance of administrative support to the success of women coaches. One study, however, has suggested that a lack of administrative support can help explain why women are leaving the coaching profession (Kamphoff, 2010). Several of the participants in Kamphoff's study cited the lack of support as critical in their decision to leave coaching and the ways the women described their administrators was "sexist," "homophobic," and "controlling." It seems that a supportive administration is key to the success of all women coaches, and maybe even more important for women who coach men particularly because women coaching men is viewed as less acceptable in the U.S. society (Yiamouyiannis, 2007).

Furthermore, athletic directors typically serve as the "gate keeper" of athletic departments and typically hire, maintain, and promote coaches. They are in a direct position to hire more women in positions to coach men. Hence, it is particularly important that athletic directors be aware that women can coach men and actively recruit women for men's coaching positions. This would mean that athletic directors should also acknowledge their own biases that may perpetuate the lack of women coaches. In fact, the majority $(80.9 \%)$ of all collegiate athletic directors are male and the NCAA Division I has the lowest percentage of female athletic directors $(9 \%)$ (Acosta \& Carpenter, 2010); hence, male athletic directors may be a part of the "old boys club." As indicated in this study, some athletic directors do believe women can coach men and even have directly asked some women to apply for coaching positions of men's teams. For the numbers of women coaching men to increase, it will take steps from athletic directors to encourage women to apply for positions coaching men.

\section{Future Research and Limitations of Current Research}

More research is needed regarding women's experiences coaching men at all levels beyond the U.S. collegiate level including the youth, high school, and other collegiate levels (such as NCAA Division II, III or NAIA). This is one study and 
generalizations cannot be made regarding all women's experience coaching men; hence, more research is needed to confirm the findings. In addition, a unique area that needs to be further developed is athletic administrators' perceptions of women coaching men. This research would be particularly important because athletic directors hire, maintain, and promote coaches. Additional research could investigate athletic administrators' perceptions at various levels of sport including collegiate and high school. Furthermore, it may prove useful to examine the perceptions of women who coach women and inquire about their interest as well as their intent of coaching men to see if they believe the opportunity to coach men is open to them. It would be interesting to specifically examine the perceptions of women coaches who have been very successful coaching women to determine their interest in coaching men. Designing this type of study could identify perceived barriers that may prohibit women from coaching men as well as strategies to address those perceived barriers.

\section{Acknowledgments}

The authors would like to thank the following graduate students who contributed to this research project: Charles Baldo, Chelsie Daniels, Aaron Haddy, Robert Hastings, Chris Jacobson, and Amber Stoltenberg, as well as the anonymous reviewer who provided comments on this manuscript.

\section{References}

Acosta, V.R., \& Carpenter, L.J. (2010). Women in intercollegiate sport: A longitudinal, national study thirty-three year update 1977-2010. Unpublished document. Brooklyn College, Brooklyn, NY, Retrieved from http://www.acostacarpenter.org/.

Associated Press. (2010, February 12). Alaskan boys hockey team rare female coach. Retrieved from http://highschool.rivals.com/content.asp?CID $=1051468$

Brand, M. (2003). Title IX seminar keynote address April 28, 2003 Myles Brand, NCAA president. Retrieved from http://www.ncaa.org/

Coakley, J.J. (2004). Sports in society: Issues and controversies (8th ed.). New York: McGraw-Hill.

Creswell, J.W. (1998). Qualitative inquiry and research design: Choosing among five traditions. Thousand Oaks, CA: Sage Publications.

Gunderson, D. (2009, December 29). Female coach a rare sight for boys' high school teams. Minnesota Public Radio. Retrieved from http://minnesota.publicradio.org/display/ web/2009/12/28/women-coaches/

Hall, M.A. (1996). Feminism and sporting bodies: Essays on theory and practice. Champaign, IL: Human Kinetics.

Halley, J. (2010, March 11). Washington D.C. woman lands prep football head coaching gig. USA Today. Retrieved from http://www.usatoday.com/sports/preps/football/201003-11-washington-dc-woman-lands-prep-football-coaching-job_N.htm.

Inglis, S., Danylchuk, K.E., \& Pastore, D.L. (2000). Multiple realities of women's work experiences in coaching and athletic management. Women in Sport \& Physical Activity Journal, 9, 1-14.

Kamphoff, C. (2010). Bargaining with patriarchy: Former women coaches' experiences and their decision to leave collegiate coaching. Research Quarterly for Exercise and Sport 81(3), 367-379. 
Kane, M.J., \& Stangl, J.M. (1991). Employment patterns of female coaches in men's athletics: Tokenism and marginalization as reflections of occupation sex-segregation. Journal of Sport and Social Issues, 15, 21-41.

Kanter, R.M. (1977). Men and women of the corporation. New York: Basic Books.

Staurowsky, E.J. (1990). Women coaching male athletes. In M.A. Messner \& D.F. Sabo (Eds.), Sport, men, and the gender order: Critical feminist perspectives (pp. 163-170). Champaign, IL: Human Kinetics.

Theberge, N. (1993). The construction of gender in sport: Women, coaching, and the naturalization of difference. Social Problems, 40, 301-313.

Thorngren, C.M. (1990). A time to reach out - Keeping the female coach in coaching. Journal of Physical Education, Recreation \& Dance, 61, 57-60.

Yiamouyiannis, A. (2007). Occupational closure in intercollegiate athletics female head coaches of men's sport teams at NCAA colleges (Unpublished doctoral dissertation). The George Washington University 